\title{
Evaluation of the photosynthetic characteristics of upland cotton (Gossypium hirsutum L.) germplasm based on chlorophyll a fluorescence
}

\author{
Y. SUN", X.M. XU ${ }^{* *}$, Y.H. JIA ${ }^{* * *}$, W.Q. DONG ${ }^{*}$, X.M. DU**,+, H.Q. DENG ${ }^{\#,+}$, and C.M. TANG ${ }^{*,+}$ \\ State Key Laboratory of Crop Genetics and Germplasm Enhancement, College of Agriculture, Nanjing Agricultural \\ University, 210095 Nanjing, Jiangsu, China* \\ Colleges of Life Science, Nanjing Agricultural University, 210095 Nanjing, Jiangsu, China** \\ State Key Laboratory of Cotton Biology, Institute of Cotton Research of CAAS, 455000 Anyang, Henan, China ${ }^{* * *}$ \\ Taicang Cotton Breeding Center, Taicang, Jiangsu, China
}

\begin{abstract}
Handy Plant Efficiency Analyser (Handy PEA) provides a method for the high-throughput screening of photosynthetic germplasm. However, the large number of chlorophyll $a$ fluorescence parameters (CFPs) from PEA and the inconsistency of CFP applications among studies greatly limit the accuracy of photosynthesis analyses. In this study, all 53 CFPs of 186 upland cotton cultivars (strains) were measured at 12:00 and 17:00 h. Thirty-two CFPs were selected according to biological importance, and the CFP relationships were determined. Differences in the response ability of cotton cultivars (strains) to high light intensity stress were demonstrated by the distribution of CFPs. Furthermore, the classification and evaluation of photosynthetic characteristics of cotton cultivars (strains) were carried out by Principal Component Analysis and Cluster Analysis. Finally, ten cotton cultivars (strains) with good photosynthetic performance were selected. This study provides a high-throughput method how to identify cotton germplasm resources with high photosynthetic efficiency.
\end{abstract}

Keywords: chlorophyll $a$ fluorescence parameter; Handy PEA; upland cotton germplasm.

\section{Introduction}

Various germplasm resources with genetic diversity are the basis of breeding. The identification of germplasm resources is an important aspect of breeding. Photosynthetic product accumulation is the basis of crop growth and development (Long et al. 2006, Zhu et al. 2012). Therefore, it is important to evaluate germplasm resources with different photosynthetic activities.
Chlorophyll $a$ fluorescence (CF) is a reliable, popular and high-throughput tool for use in photosynthesis research (Stirbet et al. 2018). CF signals contain rich photosynthesis information and may be widely used to quickly monitor the state of leaf photosynthesis in plants under stress (Sonobe et al. 2018), such as temperature (Rapacz 2007, Stefanov et al. 2011), moisture (Tsonev et al. 2011), salt (Gonzalez-Mendoza et al. 2011), nutrient elements (Kalaji et al. 2018), plant senescence (Cordon

\section{Highlights}

- Handy PEA was used to evaluate the photosynthetic characteristics of 186 cotton germplasm resources at high throughput

- Out of total 53 chlorophyll $a$ fluorescence parameters, 32 were selected according to their biological importance

- Finally, ten cotton cultivars (strains) with excellent photosynthetic characteristics were selected
Received 22 July 2021

Accepted 8 September 2021

Published online 16 December 2021

${ }^{+}$Corresponding authors

e-mail: duxiongming@caas.cn (X.M. Du) tangcm@njau.edu.cn (C.M. Tang)

Abbreviations: 10RC/ABS - optical reaction centre coefficient; ABS - absorbed light energy; CA - Cluster Analysis; CF - chlorophyll a fluorescence; CFPs - chlorophyll $a$ fluorescence parameters; CS - unit exposed area; $\mathrm{ET}_{0}$ - energy of light of PSII used to transmit electrons; KMO - Kaiser-Meyer-Olkin; PC - principal component; PCA - Principal Component Analysis; RE $\mathrm{R}_{0}$ - energy of light of PSI used to transmit electrons; $\mathrm{TR}_{0}$ - captured light energy which is used to restore $\mathrm{Q}_{\mathrm{A}}$.

Conflict of interest: The authors declare that they have no conflict of interest. 
et al. 2016), and pathogen infection (Barón et al. 2016, Ivanov and Bernards 2016).

Although CFPs can be used to evaluate plant photosynthesis rapidly and efficiently, there are numerous parameters, and most studies only select a few (Juneau et al. 2007). $\mathrm{F}_{\mathrm{v}} / \mathrm{F}_{\mathrm{m}}$ was used to investigate the effect of warming and drought on the CFPs of dominant species of Mediterranean shrubland (Prieto et al. 2009). The change in photosynthesis under salt stress in rapeseed was investigated with ten CFPs, such as $\mathrm{ET}_{0} / \mathrm{ABS}, \mathrm{F}_{0}, \mathrm{~F}_{\mathrm{v}}$, $\mathrm{F}_{\mathrm{m}}, \mathrm{F}_{\mathrm{v}} / \mathrm{F}_{\mathrm{m}}, \mathrm{PI}_{(\mathrm{abs})}, \varphi_{\mathrm{Eo}}, \mathrm{RC} / \mathrm{ABS}, \varphi_{\mathrm{Do}}$, and $\psi_{0}$ (Bacarin et al. 2011). The natural ageing of leaves was examined using five CFPs, $\mathrm{ET}_{0} / \mathrm{CS}_{0}, \mathrm{~F}_{\mathrm{v}} / \mathrm{F}_{\mathrm{m}}, \mathrm{F}_{0}, \mathrm{~F}_{\mathrm{m}}$, and $\mathrm{PI}_{\text {(abs) }}$ (Li et al. 2009). The selection of limited CFPs for analyses limits the accuracy of the interpretation of the photosynthetic activity.

Principal Component Analysis (PCA) aims to use the concept of 'dimension reduction' to transform multiple indices into a few comprehensive indices. PCA is an effective method for in-depth analysis of JIP-test fluorescence parameters. The hidden information in the large data of the fluorescence parameters can be identified using PCA (Goltsev et al. 2012).

The present study examined 53 CFPs of 186 upland cotton cultivars (strains) (the germplasms were provided by the Institute of Cotton Research of CAAS) that were evaluated at noon (the plants were exposed to high-light intensity stresses leading to depression of photosynthesis at $12: 00 \mathrm{~h}$ ) and $17: 00 \mathrm{~h}$ (the plants were not subjected to high-intensity stresses at 17:00 h) using PEA (Maai et al. 2020). The cotton cultivars (strains) were classified and evaluated by PCA and Cluster Analysis (CA). A method for high-throughput analysis of the photosynthetic potential of upland cotton germplasms was established.

\section{Materials and methods}

Plant materials: A total of 186 upland cotton cultivars (strains) were included in the study, the names of which are provided in Table 1S (supplement).

Chl $\boldsymbol{a}$ fluorescence measurement: A total of 186 cotton cultivars (strains) were grown in an experimental field under natural conditions in Anyang, China, in August 2012. Cotton cultivars (strains) were planted according to the management method of field production. During the flowering period of cotton, fluorescence data were measured at 12:00 and 17:00 h using a Handy PEA (Hansatech Instruments Ltd., Norfolk, UK) according to Strasser et al. (2001). Leaves of upland cotton cultivars (strains) were kept in the dark for at least $30 \mathrm{~min}$. After dark treatment, Chl a fluorescence induction curves were measured using PEA with red irradiance of 3,000 $\mu$ mol(photon) $\mathrm{m}^{-2} \mathrm{~s}^{-1}$. Measurements were repeated six times for each cultivar (strain). The significance of CFPs is shown in Table 1. Measurements were performed at 12:00 and 17:00 $\mathrm{h}$ on the same day. The results in our study are valid for the same or a similar climate. Each upland cotton cultivar (strain) had optimal growing conditions and the obtained results may be different under other climatic conditions.

Data analysis: Measured signals were analysed using Biolyzer 4HP software version 4.0.30.03.02 according to the JIP-test. The extracted parameters $\left(\mathrm{F}_{0}, \mathrm{~F}_{1}, \mathrm{~F}_{2}, \mathrm{~F}_{3}, \mathrm{~F}_{4}\right.$, $\mathrm{F}_{5}$, and $\mathrm{F}_{\mathrm{m}}$ ) were calculated to derive all 53 CFPs (see Appendix).

Statistical analysis: The calculation of the median, interquartile range, mean, and Mann-Whitney's $U$ test of CFPs at 12:00 and 17:00 h was performed by Excel 2013 and SPSS 19.0. The data of 186 cultivars (strains) of 32 parameters were input into SPSS 19.0, and the PCA was performed by 'Analysis - Data reduction - Factor Principal components'. Principal components of PCA were put into OriginPro 2021 for UPGMA of system clustering.

\section{Results}

Selection of CFPs: A total of 53 CFPs were derived from the $P E A . \mathrm{F}_{1}, \mathrm{~F}_{2}, \mathrm{~F}_{3}, \mathrm{~F}_{4}, \mathrm{~F}_{5}, \mathrm{~F}_{\mathrm{m}}, \mathrm{V}_{\mathrm{I}}$, and $\mathrm{V}_{\mathrm{J}}$ are the points representing the fluorescence intensity on the OJIP kinetics curve. $\mathrm{dV} / \mathrm{dT}_{0}$ and $\mathrm{dVG} / \mathrm{dT}_{0}$ represent the slope of the OJIP kinetics curve at 300 and $100 \mathrm{~s}$, respectively. These ten parameters have no obvious biological meaning in the evaluation of the photosynthetic performance of germplasm resources.

SumK $=K_{p}+K_{n}, \varphi_{\text {Po }}=1-\varphi_{\text {Do }}, F_{0} / F_{m}=\varphi_{\text {Do }}, F_{v} / F_{m}=$

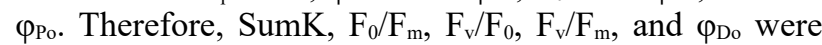
eliminated, but $K_{p}, K_{n}$, and $\varphi_{P_{0}}$ were retained.

Due to the existence of $\delta_{\mathrm{Ro}}, \psi_{0}, \varphi_{\mathrm{Po}}$ and $\mathrm{ABS} / \mathrm{RC}$, the CFPS $\delta_{\mathrm{Ro}} /\left(1-\delta_{\mathrm{Ro}}\right), \psi_{0} /\left(1-\psi_{0}\right), \varphi_{\mathrm{Po}} /\left(1-\varphi_{\mathrm{Po}}\right)$, D.F., and $10 \mathrm{RC} / \mathrm{ABS}$ were removed from evaluating cotton photosynthesis due to their relative redundancy. Finally, 32 CFPs were selected for follow-up analysis.

Statistical analysis of CFPs: The variations in the 32 CFPs were determined for the leaves of 186 upland cotton cultivars (strains) at 12:00 and 17:00 h. The Mann-Whitney's $U$ test showed that four CFPs were insignificantly but 28 CFPs were significantly different between 12:00 and 17:00 h (Table 1). This difference may be due to environmental differences, such as temperature, strong light intensity, and other stresses between 12:00 and 17:00 h. Therefore, it is necessary to measure different times of the day when evaluating the photosynthetic performance of cotton cultivars (strains).

Distribution of CFPs of upland cotton cultivars (strains): At 12:00 h, the distribution range of CFPs of cotton cultivars (strains) was widespread. Moreover, 16 parameters, such as $\mathrm{ABS} / \mathrm{RC}, \mathrm{F}_{0}, \mathrm{ABS} / \mathrm{CS}_{\mathrm{m}}, \mathrm{TR}_{0} / \mathrm{CS}_{0}$, $\mathrm{ET}_{0} / \mathrm{CS}_{0}, \mathrm{DI}_{0} / \mathrm{RC}, \mathrm{DI}_{0} / \mathrm{CS}_{0}, \mathrm{DI}_{0} / \mathrm{CS}_{\mathrm{m}}, \varphi_{\mathrm{Po}}, \mathrm{RE}_{0} / \mathrm{RC}, \mathrm{RE}_{0} / \mathrm{CS}_{0}$, $\mathrm{K}_{\mathrm{p}}, \mathrm{K}_{\mathrm{n}}, \mathrm{RC} / \mathrm{CS}_{0}, \mathrm{~N}$, and $\mathrm{S}_{\mathrm{m}} / \mathrm{T}$ showed two-peak distribution (Fig. 1S, supplement). At 17:00 h, the distribution range of CFPs of cotton cultivars (strains) was narrower. The distribution of CFPs clearly showed that different cotton cultivars (strains) responded differently to high temperature and light intensity at noon. 
Table 1. Chlorophyll $a$ fluorescence parameters of leaves at 12:00 and 17:00 h in upland cotton cultivars.

\begin{tabular}{|c|c|c|c|c|c|c|c|c|}
\hline Parameter & $\begin{array}{l}\text { Median at } \\
12: 00 \mathrm{~h}\end{array}$ & $\begin{array}{l}\text { Interquartile } \\
\text { range at } 12: 00 \mathrm{~h}\end{array}$ & $\begin{array}{l}\text { Mean at } \\
12: 00 \mathrm{~h}\end{array}$ & $\begin{array}{l}\text { Median at } \\
17: 00 \mathrm{~h}\end{array}$ & $\begin{array}{l}\text { Interquartile } \\
\text { range at 17:00 h }\end{array}$ & $\begin{array}{l}\text { Mean at } \\
17: 00 \mathrm{~h}\end{array}$ & $Z$-value & $P$-value \\
\hline $\mathrm{F}_{0}$ & 437.708 & 160.417 & 404.013 & 359.083 & 47.467 & 361.423 & -2.526 & 0.012 \\
\hline$\varphi_{\mathrm{Po}_{\mathrm{o}}}$ & 0.773 & 0.053 & 0.776 & 0.805 & 0.026 & 0.803 & -8.608 & 0.000 \\
\hline$\varphi_{\text {Eo }}$ & 0.472 & 0.474 & 0.470 & 0.546 & 0.043 & 0.544 & -13.890 & 0.000 \\
\hline$\varphi_{\text {Do }}$ & 0.227 & 0.053 & 0.224 & 0.195 & 0.025 & 0.197 & -8.610 & 0.000 \\
\hline $\mathrm{S}_{\mathrm{m}}$ & 33.998 & 8.404 & 33.669 & 35.641 & 3.991 & 35.491 & -3.371 & 0.001 \\
\hline $\mathrm{N}$ & 52.927 & 18.631 & 52.304 & 52.234 & 5.583 & 52.159 & -0.068 & 0.945 \\
\hline $\mathrm{K}_{\mathrm{p}}$ & 1.574 & 0.810 & 1.779 & 1.993 & 0.330 & 2.000 & -4.327 & 0.000 \\
\hline $\mathrm{K}_{\mathrm{n}}$ & 0.486 & 0.073 & 0.494 & 0.483 & 0.026 & 0.484 & -1.558 & 0.119 \\
\hline $\mathrm{ABS} / \mathrm{RC}$ & 2.020 & 0.365 & 2.009 & 1.824 & 0.169 & 1.840 & -7.404 & 0.000 \\
\hline $\mathrm{TR}_{0} / \mathrm{RC}$ & 1.565 & 0.185 & 1.553 & 1.473 & 0.102 & 1.475 & -6.544 & 0.000 \\
\hline $\mathrm{ET}_{0} / \mathrm{RC}$ & 0.941 & 0.129 & 0.937 & 1.000 & 0.064 & 0.995 & -6.588 & 0.000 \\
\hline $\mathrm{DI}_{0} / \mathrm{RC}$ & 0.464 & 0.188 & 0.457 & 0.358 & 0.073 & 0.364 & -8.117 & 0.000 \\
\hline $\mathrm{RE}_{0} / \mathrm{RC}$ & 0.625 & 0.136 & 0.624 & 0.503 & 0.038 & 0.502 & -14.427 & 0.000 \\
\hline $\mathrm{RE}_{0} / \mathrm{CS}_{0}$ & 154.039 & 57.242 & 142.871 & 109.946 & 11.237 & 110.699 & -9.826 & 0.000 \\
\hline $\mathrm{RC} / \mathrm{CS}_{0}$ & 233.774 & 44.198 & 227.175 & 221.489 & 15.081 & 221.217 & -2.675 & 0.007 \\
\hline $\mathrm{TR}_{0} / \mathrm{CS}_{0}$ & 373.652 & 110.062 & 353.700 & 325.162 & 32.569 & 325.796 & -2.705 & 0.007 \\
\hline $\mathrm{ET}_{0} / \mathrm{CS}_{0}$ & 226.381 & 69.006 & 213.128 & 219.225 & 14.779 & 219.590 & -0.313 & 0.754 \\
\hline $\mathrm{DI}_{0} / \mathrm{CS}_{0}$ & 112.144 & 64.771 & 105.590 & 79.359 & 20.860 & 80.641 & -6.090 & 0.000 \\
\hline $\mathrm{PI}_{(\mathrm{abs})}$ & 2.790 & 1.457 & 2.994 & 4.961 & 1.802 & 5.065 & -13.124 & 0.000 \\
\hline $\mathrm{PI}_{(\text {abs, total) }}$ & 5.749 & 1.717 & 5.966 & 5.125 & 1.751 & 5.220 & -4.628 & 0.000 \\
\hline$\delta_{\mathrm{Ro}}$ & 0.670 & 0.073 & 0.667 & 0.505 & 0.038 & 0.504 & -16.621 & 0.000 \\
\hline $\mathrm{RC} / \mathrm{CS}_{\mathrm{m}}$ & $1,017.719$ & 89.570 & $1,025.545$ & $1,142.762$ & 107.000 & $1,024.156$ & -11.210 & 0.000 \\
\hline $\mathrm{ABS} / \mathrm{CS}_{\mathrm{m}}$ & $2,061.750$ & 302.290 & $2,040.232$ & $2,077.833$ & 113.330 & $2,073.044$ & -1.525 & 0.127 \\
\hline $\mathrm{TR}_{0} / \mathrm{CS}_{\mathrm{m}}$ & $1,577.069$ & 143.855 & $1,581.249$ & $1,673.572$ & 117.305 & $1,666.846$ & -8.418 & 0.000 \\
\hline $\mathrm{ET}_{0} / \mathrm{CS}_{\mathrm{m}}$ & 965.418 & 127.750 & 959.340 & $1,141.708$ & 122.831 & $1,130.597$ & -13.264 & 0.000 \\
\hline $\mathrm{DI}_{0} / \mathrm{CS}_{\mathrm{m}}$ & 491.779 & 173.586 & 458.983 & 404.926 & 53.332 & 406.198 & -3.605 & 0.000 \\
\hline $\mathrm{SFI}_{(\mathrm{ABS})}$ & 2.344 & 0.621 & 2.403 & 3.002 & 0.427 & 2.997 & -12.014 & 0.000 \\
\hline$\phi_{\mathrm{Ro}_{\mathrm{o}}}=\mathrm{RE}_{0} / \mathrm{ABS}$ & 0.313 & 0.027 & 0.312 & 0.278 & 0.029 & 0.274 & -13.251 & 0.000 \\
\hline$\rho_{\mathrm{Ro}}=\mathrm{RE}_{0} / \mathrm{TR}_{0}$ & 0.343 & 0.042 & 0.402 & 0.343 & 0.030 & 0.341 & -14.514 & 0.000 \\
\hline$\psi_{0}$ & 0.610 & 0.049 & 0.604 & 0.683 & 0.037 & 0.676 & -14.023 & 0.000 \\
\hline $\mathrm{S}_{\mathrm{m}} / \mathrm{T}$ & 0.700 & 0.039 & 0.081 & 0.095 & 0.034 & 0.093 & -6.028 & 0.000 \\
\hline $\mathrm{PI}_{(\mathrm{cso})}$ & $12,592.638$ & $3,348.985$ & $12,796.436$ & $20,027.908$ & $4,934.000$ & $20,051.311$ & -14.359 & 0.000 \\
\hline $\mathrm{PI}_{(\mathrm{csm})}$ & $58,278.458$ & $23,404.115$ & $60,258.038$ & $103,894.035$ & $37,283.424$ & $105,461.129$ & -13.782 & 0.000 \\
\hline
\end{tabular}

$\mathrm{PI}_{(\mathrm{abs})}, \mathrm{PI}_{(\mathrm{cso})}, \mathrm{PI}_{(\mathrm{csm})}, \mathrm{SFI}_{(\mathrm{ABS})}$, and $\mathrm{K}_{\mathrm{p}}$ can synthetically reflect the photochemical activity and photosynthetic structure and function of leaves. They tend to have a lowvalue distribution at 12:00 $\mathrm{h}$ and a high-value distribution at 17:00 $\mathrm{h}$ (Fig. 1S). The results showed that photosynthetic performance decreased under high temperature and strong light at noon but increased after high temperature in the afternoon.

$\mathrm{ABS} / \mathrm{RC}, \mathrm{F}_{0}, \mathrm{ABS} / \mathrm{CS}_{\mathrm{m}}, \mathrm{TR}_{0} / \mathrm{RC}, \mathrm{TR}_{0} / \mathrm{CS}_{0}, \mathrm{TR}_{0} / \mathrm{CS}_{\mathrm{m}}$, $\mathrm{DI}_{0} / \mathrm{RC}, \mathrm{DI}_{0} / \mathrm{CS}_{0}, \mathrm{DI}_{0} / \mathrm{CS}_{\mathrm{m}}$ and $\mathrm{K}_{\mathrm{n}}$ comprehensively reflect the absorption, capture, and dissipation of light energy, which overall tend to have a high-value distribution at 12:00 $\mathrm{h}$ and a low-value distribution at 17:00 h (Fig. 1S). $\mathrm{ET}_{0} / \mathrm{RC}, \mathrm{ET}_{0} / \mathrm{CS}_{0}$, and $\mathrm{ET}_{0} / \mathrm{CS}_{\mathrm{m}}$ reflect the light energy used for electron transfer, with a low overall distribution at 12:00 $\mathrm{h}$ and a high overall distribution at 17:00 $\mathrm{h}$ (Fig. 1S). $\varphi_{\mathrm{Eo}}=\mathrm{ET}_{0} / \mathrm{ABS}, \psi_{0}=\mathrm{ET}_{0} / \mathrm{TR}_{0}$, and $\varphi_{\mathrm{Po}}=\mathrm{TR}_{0} / \mathrm{ABS}$ reflect the ratio of the light energy used for electron transfer to the light energy absorbed and captured to the light energy absorbed, respectively, which tends to be low at 12:00 h and high at 17:00 $\mathrm{h}$ (Fig. 1S). The distribution of these 16 parameters indicates that the leaf absorbs and captures more light energy at high temperature and light intensity, but less light energy is used for electron transfer and more light energy is used for heat dissipation, whereas the opposite phenomenon occurs after high temperature and light intensity in the afternoon.

$\delta_{\mathrm{Ro}}, \phi_{\mathrm{Ro}}=\mathrm{RE}_{0} / \mathrm{ABS}, \rho_{\mathrm{Ro}}=\mathrm{RE}_{0} / \mathrm{TR}_{0}$, and $\mathrm{PI}_{(\text {abs, total })}$ tended to have a high-value distribution at 12:00 $\mathrm{h}$ and a low-value distribution at 17:00 h (Fig. 1S), indicating that PSI photosynthetic performance was higher at noon and lower in the afternoon.

$\mathrm{N}, \mathrm{S}_{\mathrm{m}}$, and $\mathrm{S}_{\mathrm{m}} / \mathrm{T}$ tend to be low at 12:00 $\mathrm{h}$ and high at $17: 00 \mathrm{~h}$ (Fig. 1S), indicating that the PSII receptor 
plastoquinone pool decreased at high temperature at noon and increased after a decrease of high temperatures.

\section{Classification, screening, and evaluation of upland cotton cultivars (strains)}

PCA at 12:00 h: PCA was performed on 32 CFPs selected at 12:00 h. The existence of $\mathrm{DI}_{0} / \mathrm{RC}$ and $\mathrm{DI}_{0} / \mathrm{CS}_{\mathrm{m}}$ caused Kaiser-Meyer-Olkin (KMO) or Bartlett's test for Nonpositive Definite Matrices. Therefore, these two parameters were eliminated. Finally, PCA for $30 \mathrm{CFPs}$ was carried out. $\mathrm{KMO}>0.5, P<0.05$, and correlation analysis showed the parameters were suitable for PCA (Table 2; Table 2S, supplement). The cumulative variance contribution of the first three principal components from PCA was $86.8 \%$, which covered most of the CFP information. The first principal component provided 54.4\% of the parameter information, which had a significant positive correlation with $\mathrm{F}_{0}, \mathrm{TR}_{0} / \mathrm{CS}_{0}, \mathrm{DI}_{0} / \mathrm{CS}_{0}, \mathrm{RE}_{0} / \mathrm{CS}_{0}$, $\mathrm{ABS} / \mathrm{RC}, \mathrm{ET}_{0} / \mathrm{CS}_{0}, \mathrm{TR}_{0} / \mathrm{RC}, \mathrm{RE}_{0} / \mathrm{RC}, \mathrm{ABS} / \mathrm{CS}_{\mathrm{m}}, \mathrm{RC} / \mathrm{CS}_{0}$, and $\mathrm{N}$ and a significant negative correlation with $\mathrm{K}_{\mathrm{p}}, \varphi_{\mathrm{Po}}$, $\mathrm{K}_{\mathrm{n}}, \mathrm{SFI}_{(\mathrm{ABS})}$, and $\mathrm{PI}_{(\mathrm{abs})}$. The first principal component is a comprehensive component including PSII absorption, capture, and dissipation energy and PSI electron transfer. The second principal component provided $25 \%$ of the information about the parameters, which had a positive correlation with $\psi_{0}, \mathrm{PI}_{(\mathrm{cso})}, \mathrm{ET}_{0} / \mathrm{CS}_{\mathrm{m}}$, and $\phi_{\mathrm{Ro}}=\mathrm{RE}_{0} / \mathrm{ABS}$. The second principal component includes the energy of PSII electron transfer, the proportion of electron transfer to the light energy of capture, and the proportion of electron transfer to the light energy of PSI. The third principal component provided $7.4 \%$ of the information about the parameters. The third principal component had a positive correlation with $\delta_{\mathrm{Ro}}$ and $\phi_{\mathrm{Ro}}=\mathrm{RE}_{0} / \mathrm{ABS}$. The third principal component primarily includes the electron transfer capability of PSI (Table 3).

According to the calculated principal component coefficients, a linear combination of principal components $\mathrm{y} 1, \mathrm{y} 2$, and $\mathrm{y} 3$ was obtained (Table 3S, supplement). The relationship between the principal component and parameters can be inferred from principal component coefficients. The higher $\mathrm{yl}$ is, the greater is the light energy absorbed and captured by PSII. However, higher energy was used for heat dissipation, which led to a lower overall photosynthetic performance. The higher y2 is, the higher are the ratios of the electron transfer energy to the electron transfer energy of PSII and of the electron transfer energy of PSI to the absorption energy. The higher y 3 is, the higher is the electron transfer capability of PSI.

CA at 12:00 h: Based on $y 1, y 2$, and $y 3$, the cotton cultivars (strains) distribution and phylogenetic tree of the cluster were obtained by the scatter plot and CA (Fig. 1; Fig. 2S, supplement). The result showed that at 12:00 $\mathrm{h}$ cotton cultivars (strains) were divided into three groups according to their photosynthetic characteristics. Group I consisted of 99 cotton cultivars (strains) that absorb and capture more energy, use less energy for electron transfer, and use more energy for heat dissipation. These cultivars (strains) have a weaker overall photosynthetic capacity. Group II included 86 cotton cultivars (strains). Although the energy absorbed and captured by the leaves was low, that used for electron transfer was high, but that used for heat dissipation was low. The overall photosynthetic capacity was high. Group III included one cotton cultivar (strain), which had low energy absorbed and captured and low energy used for heat dissipation but had high energy used for electron transfer. The overall photosynthetic capacity of the cotton was high. The classification of the photosynthetic characteristics of cotton cultivars (strains) was clearly performed by CA (Table 4S, supplement; Fig. 2S).

PCA at 17:00: The existence of $\mathrm{DI}_{0} / \mathrm{RC}$ and $\mathrm{DI}_{0} / \mathrm{CS}_{\mathrm{m}}$ also caused KMO or Bartlett's test for Nonpositive Definite Matrices. Therefore, the two parameters were eliminated. $\mathrm{KMO}>0.5, P<0.05$, and correlation analysis showed 30 parameters were suitable for PCA (Table 4; Table 5S, supplement). The cumulative variance contribution of the first three principal components was $84.1 \%$, which covered most of the chlorophyll fluorescence parameters. The first principal component can provide $48.9 \%$ of the parameter information, which had a significant positive correlation with $\mathrm{PI}_{(\mathrm{abs})}, \mathrm{SFI}_{(\mathrm{ABS})}, \mathrm{PI}_{(\mathrm{csm})}, \mathrm{PI}_{(\mathrm{cso})}, \varphi_{\mathrm{Po}}, \varphi_{\mathrm{Eo}}$, $\mathrm{PI}_{\text {(abs, total) }}, \psi_{0}, \mathrm{~K}_{\mathrm{p}}, \mathrm{RC} / \mathrm{CS}_{\mathrm{m}}$, and $\mathrm{ET}_{0} / \mathrm{CS}_{\mathrm{m}}$ and a significant negative correlation with $\mathrm{DI}_{0} / \mathrm{CS}_{0}, \mathrm{~F}_{0}$, and $\mathrm{ABS} / \mathrm{RC}$. It contained PSII absorption, electron transfer, dissipated energy, the proportion of energy used for electron transfer, and a comprehensive composition of PSII and PSI electron transfer. The first principal component is highly comprehensive. The second principal component provided $20.2 \%$ of the information on parameters, which was positively correlated with $\mathrm{RE}_{0} / \mathrm{CS}_{0}$ and $\mathrm{ET}_{0} / \mathrm{CS}_{0}$. The second principal component contained information such as the energy per unit area used for electron transfer. The third principal component provided $14.9 \%$ of the parameter information. The third principal component had a positive correlation with $\delta_{\text {Ro }}$, which mainly reflects PSI electron transfer efficiency (Table 5).

According to the calculated principal component coefficients, a linear combination of principal components $\mathrm{y} 1, \mathrm{y} 2$, and $\mathrm{y} 3$ was obtained (Table 6S, supplement). The higher $\mathrm{y} 1$ is, the higher is the proportion of absorbed PSII and captured energy for electron transfer, the smaller is the proportion of heat dissipation and the higher the

Table 2. KMO and Bartlett's test at 12:00 h.

Kaiser-Meyer-Olkin measure of sampling adequacy

Bartlett's test of sphericity
0.71

Approx. chi-square $\quad 29,805.173$

df $\quad 435$

Sig. 0 
Table 3. Component eigenvalues and component matrices of Principal Component Analysis at 12:00 h.

\begin{tabular}{|c|c|c|c|c|c|c|c|}
\hline \multirow[t]{2}{*}{ Component } & \multicolumn{3}{|c|}{ Initial eigenvalues } & \multirow[t]{2}{*}{ Parameter } & \multicolumn{3}{|c|}{ Component } \\
\hline & Total & Variance $[\%]$ & Cumulative [\%] & & 1 & 2 & 3 \\
\hline 1 & 16.331 & 54.437 & 54.437 & Zscore $\left(\mathrm{K}_{\mathrm{p}}\right)$ & -0.988 & 0.047 & 0.060 \\
\hline 2 & 7.500 & 25.000 & 79.436 & Zscore $\left(\mathrm{F}_{0}\right)$ & 0.986 & 0.023 & -0.052 \\
\hline 3 & 2.214 & 7.380 & 86.816 & Zscore $\left(\mathrm{TR}_{0} / \mathrm{CS}_{0}\right)$ & 0.986 & 0.037 & -0.111 \\
\hline 4 & 1.479 & 4.930 & 91.746 & Zscore $\left(\mathrm{DI}_{0} / \mathrm{CS}_{0}\right)$ & 0.977 & -0.110 & 0.001 \\
\hline 5 & 1.210 & 4.034 & 95.780 & Zscore $\left(\mathrm{RE}_{0} / \mathrm{CS}_{0}\right)$ & 0.950 & 0.277 & 0.121 \\
\hline 6 & 0.519 & 1.731 & 97.511 & $\operatorname{Zscore}\left(\varphi_{\mathrm{Po}_{\mathrm{o}}}\right)$ & -0.948 & 0.227 & -0.089 \\
\hline 7 & 0.393 & 1.309 & 98.820 & Zscore(ABS/RC) & 0.940 & -0.169 & -0.089 \\
\hline 8 & 0.166 & 0.554 & 99.374 & Zscore $\left(\mathrm{ET}_{0} / \mathrm{CS}_{0}\right)$ & 0.902 & 0.389 & -0.150 \\
\hline 9 & 0.098 & 0.327 & 99.700 & Zscore $\left(\mathrm{TR}_{0} / \mathrm{RC}\right)$ & 0.877 & -0.128 & -0.178 \\
\hline 10 & 0.035 & 0.117 & 99.818 & Zscore $\left(\mathrm{RE}_{0} / \mathrm{RC}\right)$ & 0.874 & 0.323 & 0.217 \\
\hline 11 & 0.020 & 0.068 & 99.885 & Zscore $\left(\mathrm{ABS} / \mathrm{CS}_{\mathrm{m}}\right)$ & 0.871 & 0.314 & -0.327 \\
\hline 12 & 0.013 & 0.045 & 99.930 & Zscore $\left(K_{n}\right)$ & -0.871 & -0.323 & 0.310 \\
\hline 13 & 0.006 & 0.020 & 99.950 & Zscore $\left(\mathrm{SFI}_{(\mathrm{ABS})}\right)$ & -0.863 & 0.491 & 0.024 \\
\hline 14 & 0.005 & 0.017 & 99.968 & Zscore $\left(\mathrm{RC} / \mathrm{CS}_{0}\right)$ & 0.858 & 0.153 & -0.040 \\
\hline 15 & 0.004 & 0.013 & 99.981 & Zscore $(\mathrm{N})$ & 0.829 & 0.467 & 0.158 \\
\hline 16 & 0.003 & 0.009 & 99.989 & Zscore $\left(\mathrm{PI}_{(\mathrm{abs})}\right)$ & -0.822 & 0.541 & -0.030 \\
\hline 17 & 0.001 & 0.003 & 99.992 & Zscore $\left(\mathrm{PI}_{(\mathrm{csm})}\right)$ & -0.695 & 0.681 & -0.137 \\
\hline 18 & 0.001 & 0.002 & 99.994 & Zscore $\left(\mathrm{TR}_{0} / \mathrm{CS}_{\mathrm{m}}\right)$ & 0.588 & 0.553 & -0.501 \\
\hline 19 & 0.001 & 0.002 & 99.996 & Zscore $\left(\psi_{0}\right)$ & -0.105 & 0.912 & -0.112 \\
\hline 20 & 0.000 & 0.001 & 99.998 & Zscore $\left(\mathrm{PI}_{(\mathrm{cso})}\right)$ & -0.432 & 0.872 & -0.164 \\
\hline 21 & 0.000 & 0.001 & 99.999 & Zscore $\left(\mathrm{ET}_{0} / \mathrm{CS}_{\mathrm{m}}\right)$ & 0.294 & 0.869 & -0.374 \\
\hline 22 & 0.000 & 0.001 & 99.999 & $\operatorname{Zscore}\left(\phi_{\mathrm{Ro}}=\mathrm{RE}_{0} / \mathrm{ABS}\right)$ & 0.129 & 0.820 & 0.525 \\
\hline 23 & $8.14 \times 10^{-5}$ & 0.000 & 100.000 & $\operatorname{Zscore}\left(\varphi_{\mathrm{Eo}}\right)$ & -0.509 & 0.799 & -0.127 \\
\hline 24 & $6.28 \times 10^{-5}$ & 0.000 & 100.000 & Zscore $\left(\mathrm{S}_{\mathrm{m}}\right)$ & 0.604 & 0.675 & 0.298 \\
\hline 25 & $2.92 \times 10^{-5}$ & $9.74 \times 10^{-5}$ & 100.000 & $\operatorname{Zscore}\left(\rho_{\mathrm{Ro}}=\mathrm{RE}_{0} / \mathrm{TR}_{0}\right)$ & 0.543 & 0.649 & 0.516 \\
\hline 26 & $1.71 \times 10^{-5}$ & $5.70 \times 10^{-5}$ & 100.000 & Zscore $\left(\mathrm{RC} / \mathrm{CS}_{\mathrm{m}}\right)$ & -0.483 & 0.612 & -0.197 \\
\hline 27 & $1.24 \times 10^{-5}$ & $4.14 \times 10^{-5}$ & 100.000 & Zscore $\left(\mathrm{PI}_{(\mathrm{abs}, \text { total })}\right)$ & -0.537 & 0.605 & 0.489 \\
\hline 28 & $5.34 \times 10^{-6}$ & $1.78 \times 10^{-5}$ & 100.000 & Zscore $\left(\delta_{\mathrm{Ro}}\right)$ & 0.659 & -0.052 & 0.670 \\
\hline 29 & $2.31 \times 10^{-6}$ & $7.70 \times 10^{-6}$ & 100.000 & Zscore $\left(\mathrm{S}_{\mathrm{m}} / \mathrm{T}\right)$ & 0.198 & 0.109 & 0.034 \\
\hline 30 & $3.32 \times 10^{-7}$ & $1.11 \times 10^{-6}$ & 100.000 & Zscore $\left(\mathrm{ET}_{0} / \mathrm{RC}\right)$ & -0.134 & -0.119 & -0.094 \\
\hline
\end{tabular}

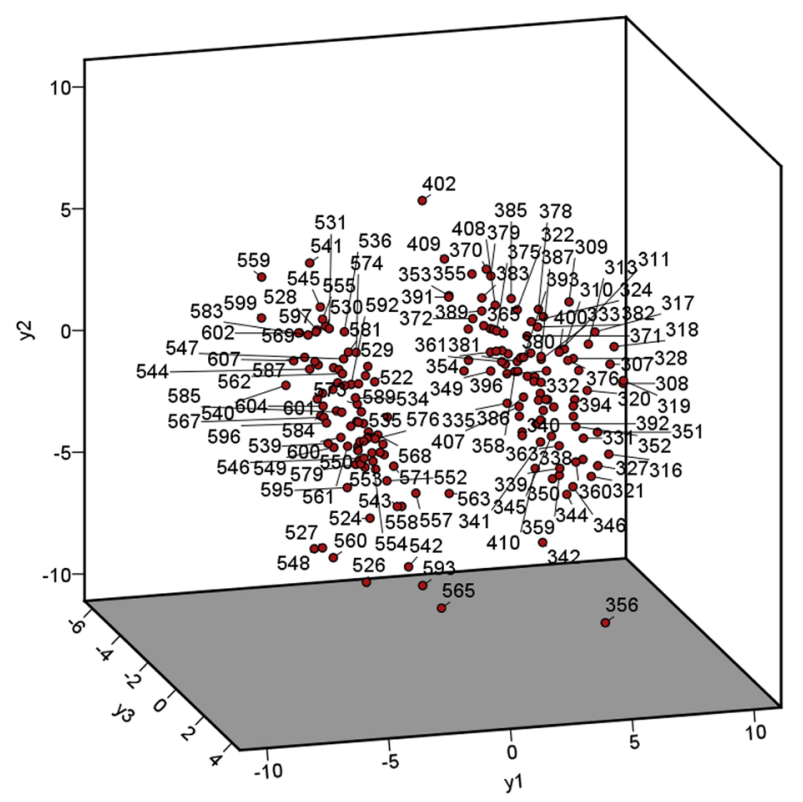

photosynthetic energy utilization ratio. The higher y2 is, the more energy is per unit area of PSII and PSI used for electron transfer. The higher the $\mathrm{y} 3$ value is, the higher is the PSI electron transfer efficiency.

CA at 17:00: Based on y1, y2, and y3, the phylogenetic tree of the cluster at 17:00 h was obtained by systematic CA (Fig. 2). The family tree showed that the photosynthetic characteristics of cotton cultivars (strains) were divided into seven groups after high-temperature stress in the afternoon. Group I included 93 cotton cultivars (strains) that had high energy per unit area of PSII and PSI used for electron transfer, but the comprehensive photosynthetic capacity of the cotton cultivars (strains) was low. In Group II, 80 cotton cultivars (strains) were included and their energy per unit area for electron transfer in PSII and PSI in Group II were all moderate, but the photochemical efficiency and comprehensive photosynthetic capacity of

Fig. 1. Clustering of cotton cultivars (strains) at 12:00 h. The markings on the scatter plot are cultivar numbers. 


\section{Y. SUN et al.}

Table 4. KMO and Bartlett's test at 17:00 h.

\begin{tabular}{lll}
\hline Kaiser-Meyer-Olkin measure of sampling adequacy & & 0.674 \\
Bartlett's test of sphericity & Approx. chi-square & $30,365.404$ \\
& df & 435 \\
& Sig. & 0 \\
\hline
\end{tabular}

Table 5. Component eigenvalues and component matrix of Principal Component Analysis at 17:00 h.

\begin{tabular}{|c|c|c|c|c|c|c|c|c|}
\hline \multirow[t]{2}{*}{ Component } & \multicolumn{3}{|c|}{ Initial eigenvalues } & \multirow[t]{2}{*}{ Parameter } & \multicolumn{4}{|c|}{ Component } \\
\hline & Total & Variance [\%] & Cumulative [\%] & & 1 & 2 & 3 & 4 \\
\hline 1 & 14.663 & 48.876 & 48.876 & Zscore $\left(\mathrm{PI}_{(\mathrm{abs})}\right)$ & 0.977 & -0.097 & -0.041 & 0.000 \\
\hline 2 & 6.072 & 20.240 & 69.116 & Zscore $\left(\mathrm{SFI}_{(\mathrm{ABS})}\right)$ & 0.976 & -0.088 & 0.008 & 0.133 \\
\hline 3 & 4.489 & 14.963 & 84.079 & Zscore $\left(\mathrm{PI}_{(\mathrm{csm})}\right)$ & 0.971 & -0.014 & -0.143 & 0.013 \\
\hline 4 & 2.570 & 8.566 & 92.645 & Zscore $\left(\mathrm{PI}_{(\mathrm{cso})}\right)$ & 0.961 & 0.090 & -0.143 & 0.044 \\
\hline 5 & 0.996 & 3.321 & 95.966 & Zscore $\left(\varphi_{P_{0}}\right)$ & 0.955 & -0.089 & -0.155 & -0.107 \\
\hline 6 & 0.525 & 1.751 & 97.716 & $\operatorname{Zscore}\left(\varphi_{\mathrm{Eo}}\right)$ & 0.948 & 0.194 & -0.040 & -0.161 \\
\hline 7 & 0.471 & 1.570 & 99.286 & Zscore $\left(\mathrm{DI}_{0} / \mathrm{CS}_{0}\right)$ & -0.941 & 0.238 & -0.008 & 0.127 \\
\hline 8 & 0.123 & 0.410 & 99.696 & Zscore $\left(\mathrm{PI}_{(\mathrm{abs}, \text { total })}\right)$ & 0.930 & 0.004 & 0.246 & 0.167 \\
\hline 9 & 0.033 & 0.111 & 99.807 & Zscore $\left(\mathrm{K}_{\mathrm{p}}\right)$ & 0.884 & -0.404 & 0.143 & -0.142 \\
\hline 10 & 0.029 & 0.096 & 99.904 & Zscore $\left(\psi_{0}\right)$ & 0.880 & 0.319 & 0.008 & -0.174 \\
\hline 11 & 0.009 & 0.029 & 99.933 & Zscore(ABS/RC) & -0.840 & 0.313 & -0.026 & -0.419 \\
\hline 12 & 0.006 & 0.019 & 99.951 & Zscore $\left(\mathrm{RC} / \mathrm{CS}_{\mathrm{m}}\right)$ & 0.837 & 0.040 & -0.349 & 0.393 \\
\hline 13 & 0.005 & 0.016 & 99.967 & Zscore $\left(\mathrm{ET}_{0} / \mathrm{CS}_{\mathrm{m}}\right)$ & 0.831 & 0.411 & -0.352 & -0.100 \\
\hline 14 & 0.004 & 0.012 & 99.979 & Zscore $\left(\mathrm{F}_{0}\right)$ & -0.824 & 0.471 & -0.166 & 0.205 \\
\hline 15 & 0.002 & 0.008 & 99.987 & Zscore $\left(\mathrm{TR}_{0} / \mathrm{CS}_{0}\right)$ & -0.751 & 0.550 & -0.323 & 0.145 \\
\hline 16 & 0.001 & 0.003 & 99.991 & Zscore $\left(\phi_{\mathrm{Ro}}=\mathrm{RE}_{0} / \mathrm{ABS}\right)$ & 0.727 & 0.393 & 0.524 & 0.143 \\
\hline 17 & 0.001 & 0.002 & 99.993 & Zscore $\left(\mathrm{TR}_{0} / \mathrm{RC}\right)$ & -0.673 & 0.386 & -0.110 & -0.604 \\
\hline 18 & 0.001 & 0.002 & 99.995 & Zscore $\left(\mathrm{ET}_{0} / \mathrm{CS}_{0}\right)$ & 0.017 & 0.900 & -0.336 & -0.014 \\
\hline 19 & 0.001 & 0.002 & 99.996 & Zscore $\left(\mathrm{RE}_{0} / \mathrm{CS}_{0}\right)$ & -0.096 & 0.895 & 0.320 & 0.272 \\
\hline 20 & 0.000 & 0.001 & 99.997 & Zscore $\left(\mathrm{RE}_{0} / \mathrm{RC}\right)$ & 0.072 & 0.771 & 0.563 & -0.210 \\
\hline 21 & 0.000 & 0.001 & 99.999 & Zscore $\left(\mathrm{S}_{\mathrm{m}} / \mathrm{T}\right)$ & -0.374 & 0.465 & 0.181 & 0.290 \\
\hline 22 & 0.000 & 0.001 & 99.999 & Zscore $\left(\delta_{\mathrm{Ro}}\right)$ & -0.116 & 0.374 & 0.778 & 0.374 \\
\hline 23 & $9.59 \times 10^{-5}$ & 0.000 & 99.999 & Zscore $\left(\mathrm{ABS} / \mathrm{CS}_{\mathrm{m}}\right)$ & 0.293 & 0.605 & -0.694 & 0.055 \\
\hline 24 & $5.84 \times 10^{-5}$ & 0.000 & 100.000 & Zscore $\left(K_{n}\right)$ & -0.330 & -0.604 & 0.676 & -0.057 \\
\hline 25 & $3.78 \times 10^{-5}$ & 0.000 & 100.000 & $\operatorname{Zscore}\left(\rho_{\mathrm{Ro}_{0}}=\mathrm{RE}_{0} / \mathrm{TR}_{0}\right)$ & 0.540 & 0.494 & 0.636 & 0.190 \\
\hline 26 & $2.95 \times 10^{-5}$ & $9.84 \times 10^{-5}$ & 100.000 & Zscore $\left(\mathrm{TR}_{0} / \mathrm{CS}_{\mathrm{m}}\right)$ & 0.604 & 0.436 & -0.612 & -0.001 \\
\hline 27 & $1.47 \times 10^{-5}$ & $4.90 \times 10^{-5}$ & 100.000 & Zscore $\left(\mathrm{S}_{\mathrm{m}}\right)$ & 0.508 & 0.292 & 0.603 & 0.004 \\
\hline 28 & $6.74 \times 10^{-6}$ & $2.25 \times 10^{-5}$ & 100.000 & Zscore $(\mathrm{N})$ & 0.150 & 0.515 & 0.561 & -0.317 \\
\hline 29 & $3.24 \times 10^{-6}$ & $1.08 \times 10^{-5}$ & 100.000 & Zscore $\left(\mathrm{RC} / \mathrm{CS}_{0}\right)$ & -0.298 & 0.305 & -0.315 & 0.824 \\
\hline 30 & $4.10 \times 10^{-7}$ & $1.37 \times 10^{-6}$ & 100.000 & Zscore $\left(\mathrm{ET}_{0} / \mathrm{RC}\right)$ & 0.248 & 0.643 & -0.100 & -0.682 \\
\hline
\end{tabular}

the cotton cultivars (strains) were high. In Group III, there were two cotton cultivars (strains), the light-utilization efficiency was at the middle level, but the energy per unit area for electron transfer of PSI was relatively high. Group IV included two cotton cultivars (strains) that had middle light-use efficiency and great high energy per unit area for electron transfer in PSII and PSI. Group V included one cotton cultivar (strain), which had low lightuse efficiency and electron transfer efficiency of PSI. In Group VI, there were seven cotton cultivars (strains). They had a low comprehensive photosynthetic capacity. Group VII included only one cotton cultivar (strain) that had low energy per unit area of PSII and PSI used for electron transfer (Table S7, supplement; Fig. S3, supplement).

Selection of cotton cultivars (strains) with high photosynthetic efficiency: Through Principal Component Analysis and Cluster Analysis, ten cotton cultivars (strains) with good photosynthetic performance were selected, including Nongdamian7, Zhong80, E0902, E0904, Emian18, Ekangmian9, Zaoshuchangnong7, Su7036, Suyuan04-3, and MSCO-11 (Table 6). They were all in Cluster II at 12:00 and 17:00 h. At 12:00 h, when they were exposed to high-light intensity stress, the energy absorbed 
and captured by leaves was low, that used for electron transfer was high, but that used for heat dissipation was low. In general, the photosynthetic capacity of the cultivars (strains) was high. At 17:00 h, when they were not subjected to high-light intensity stress, the photochemical efficiency and comprehensive photosynthetic capacity of the cotton cultivars (strains) were high.

\section{Discussion}

The influence of environment on CFPs of upland cotton cultivars (strains): The environment greatly influences the CFPs of many plants (Poormohammad Kiani et al. 2008, Piccotto et al. 2011). However, no research on the effects of environments on the variation in CFPs of such a large number of upland cotton cultivars (strains) during the day has been reported. The present study revealed significant differences in CFPs between high light intensity at noon

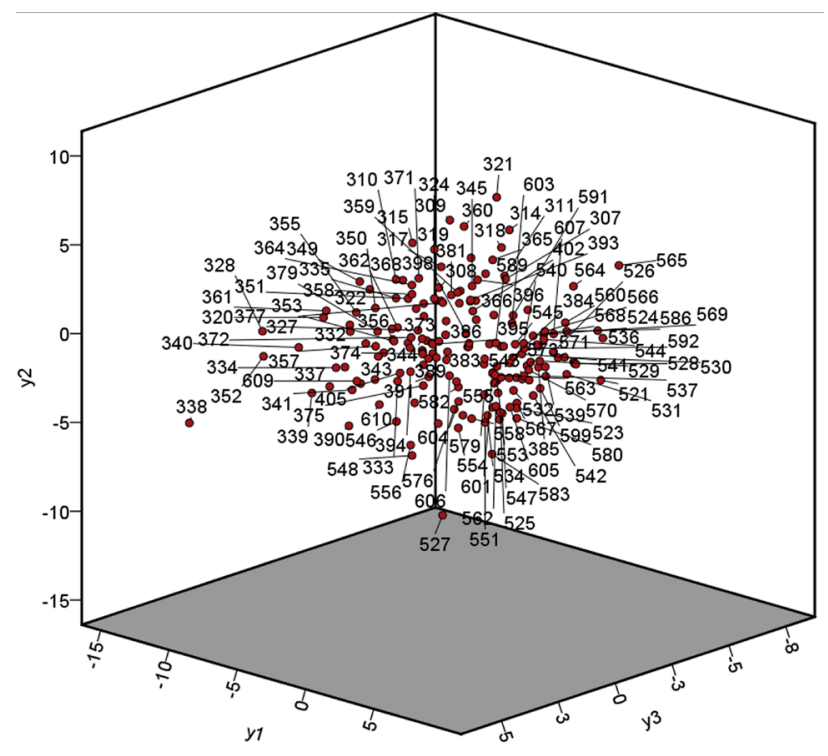

Fig. 2. Clustering of cotton cultivars (strains) at 17:00 h. The markings on the scatter plot are cultivar numbers. and low intensity in the afternoon. Therefore, it is necessary to select a representative time point in a day when CFPs are used to evaluate the photosynthesis of cotton.

Distribution of CFPs: The range of theoretical values for various CFPs is rarely reported. The list of the distribution of CFPs of the 186 cultivars (strains) provides breeders with ranges of variation between cotton cultivars (strains). The distribution of CFPs at 12:00 and 17:00 $\mathrm{h}$ reflected the photosynthetic characteristics of cotton cultivars (strains) under high temperature and high light intensity and after high temperature and high light intensity, which provides breeders with a reference.

Screening of upland cotton germplasm: CFPs have always been used to detect the response of plants to environmental stress (Oukarroum et al. 2007). Few researchers use CFPs to screen germplasm resources. Moreover, CFPs are numerous, most researchers usually select several parameters to evaluate the photosynthesis of plants and different studies often choose different parameters. Through analysing all CFPs of a large number of cotton strains, we successfully classified the cotton cultivars (strains), summarized the photosynthetic characteristics of cotton cultivars (strains), and selected the cultivars (strains) with strong photosynthetic performance. Our study provides a quick and efficient method for breeders to select high light efficient cotton germplasm, which greatly benefits breeders.

Conclusion: All CFPs of 186 cotton cultivars (strains) were measured at 12:00 and 17:00 h each day. By using nonparametric tests and frequency distributions, we analysed and compared the photosynthetic characteristics of cotton cultivars (strains) under high temperature and high light intensity at noon and after high temperature and high light intensity in the afternoon. The photosynthetic characteristics of cotton cultivars (strains) were further divided into three groups at 12:00 $\mathrm{h}$ and seven groups at 17:00 $\mathrm{h}$ by $\mathrm{CA}$, and the photosynthetic characteristics of each cotton group were evaluated. Finally, ten cotton cultivars (strains) with a good photosynthetic performance

Table 6. Top ten upland cotton cultivars (strains) according to Principal Component Analysis and Cluster Analysis.

\begin{tabular}{|c|c|c|c|c|c|c|c|}
\hline Cultivar number & Cultivar name & $\begin{array}{l}12: 00 \mathrm{~h} \\
\mathrm{y} 1\end{array}$ & y2 & y3 & $\begin{array}{l}\text { 17:00 h } \\
\text { y1 }\end{array}$ & $\mathrm{y} 2$ & y3 \\
\hline 530 & Nongdamian7 & -4.08 & 2.37 & -1.57 & 8.08 & 1.31 & 0.24 \\
\hline 531 & Zhong80 & -5.69 & 4.09 & 1.50 & 7.59 & 0.08 & -0.15 \\
\hline 536 & E0902 & -5.00 & 3.84 & 1.38 & 7.85 & 1.57 & -1.58 \\
\hline 537 & E0904 & -3.53 & 1.34 & 0.33 & 6.79 & -0.02 & 0.29 \\
\hline 545 & Emian18 & -6.26 & 5.22 & 1.86 & 5.77 & 1.87 & 1.02 \\
\hline 559 & Ekangmian9 & -6.21 & 4.08 & -2.43 & 5.72 & -0.41 & -1.68 \\
\hline 562 & Zaoshuchangnong7 & -4.74 & 1.77 & 0.79 & 7.41 & -0.48 & 2.86 \\
\hline 569 & Su7036 & -5.42 & 2.46 & -1.11 & 5.80 & 1.11 & -2.59 \\
\hline 574 & Suyuan04-3 & -4.25 & 2.68 & 0.92 & 6.18 & 0.28 & 1.53 \\
\hline 589 & MSCO-11 & -4.57 & 1.81 & 1.64 & 5.81 & 2.32 & 1.90 \\
\hline
\end{tabular}


at both 12:00 and 17:00 h were selected by PCA. This study provides a method for the identification of cotton germplasm resources with the high photosynthetic efficiency.

\section{References}

Bacarin M.A., Deuner S., Silva F.S.P. et al.: Chlorophyll a fluorescence as indicative of the salt stress on Brassica napus L. - Braz. J. Plant Physiol. 23: 245-253, 2011.

Barón M., Pineda M., Pérez-Bueno M.: Picturing pathogen infection in plants. - Z. Naturforsch. 71: 355-368, 2016.

Cordon G., Lagorio M.G., Paruelo J.M. et al.: Chlorophyll fluorescence, photochemical reflective index and normalized difference vegetative index during plant senescence. - J. Plant Physiol. 199: 100-110, 2016.

Goltsev V., Zaharieva I., Chernev P. et al.: Drought-induced modifications of photosynthetic electron transport in intact leaves: analysis and use of neural networks as a tool for a rapid non-invasive estimation. - BBA-Bioenergetics 1817: 1490-1498, 2012.

Gonzalez-Mendoza D., Espadas y Gil F., Rodriguez J.F. et al.: Photosynthetic responses of a salt secretor mangrove, Avicennia germinans, exposed to salinity stress. - Aquat. Ecosyst. Health Manag. 14: 285-290, 2011.

Ivanov D.A., Bernards M.A.: Chlorophyll fluorescence imaging as a tool to monitor the progress of a root pathogen in a perennial plant. - Planta 243: 263-279, 2016.

Juneau P., Qiu B., Deblois C.P.: Use of chlorophyll fluorescence as a tool for determination of herbicide toxic effect: Review. Toxicol. Environ. Chem. 89: 609-625, 2007.

Kalaji H.M., Bąba W., Gediga K. et al.: Chlorophyll fluorescence as a tool for nutrient status identification in rapeseed plants. Photosynth. Res. 136: 329-343, 2018.

Li R., Zhou W., Lu W.: [Changes in photosynthesis and chlorophyll fluorescence parameters during rice leaf senescence in low chlorophyll $b$ mutant.] - J. Nanjing Agric. Univ. 32: 10-14, 2009. [In Chinese]

Long S.P., Zhu X.G., Naidu S.L., Ort D.R.: Can improvement in photosynthesis increase crop yields? - Plant Cell Environ. 29: 315-330, 2006.

Maai E., Nishimura K., Takisawa R., Nakazaki T.: Light stressinduced chloroplast movement and midday depression of photosynthesis in sorghum leaves. - Plant Prod. Sci. 23:
$172-181,2020$.

Oukarroum A., El Madidi S., Schansker G., Strasser R.J.: Probing the responses of barley cultivars (Hordeum vulgare L.) by chlorophyll $a$ fluorescence OLKJIP under drought stress and re-watering. - Environ. Exp. Bot. 60: 438-446, 2007.

Piccotto M., Bidussi M., Tretiach M.: Effects of the urban environmental conditions on the chlorophyll $a$ fluorescence emission in transplants of three ecologically distinct lichens. - Environ. Exp. Bot. 73: 102-107, 2011.

Poormohammad Kiani S., Maury P., Sarrafi A., Grieu P.: QTL analysis of CFPs in sunflower (Helianthus annuus L.) under well-watered and water-stressed conditions. - Plant Sci. 175: 565-573, 2008.

Prieto P., Peñuelas J., Llusià J. et al:: Effects of longterm experimental night-time warming and drought on photosynthesis, $\mathrm{F}_{\mathrm{v}} / \mathrm{F}_{\mathrm{m}}$ and stomatal conductance in the dominant species of a Mediterranean shrubland. - Acta Physiol. Plant. 31: 729-739, 2009.

Rapacz M.: Chlorophyll $a$ fluorescence transient during freezing and recovery in winter wheat. - Photosynthetica 45: 409-418, 2007.

Sonobe R., Wang Q.: Assessing hyperspectral indices for tracing CFPs in deciduous forests. - J. Environ. Manage. 227: 172$180,2018$.

Stefanov D., Petkova V., Denev I.D.: Screening for heat tolerance in common bean (Phaseolus vulgaris L.) lines and cultivars using JIP-test. - Sci. Hortic.-Amsterdam 128: 1-6, 2011.

Stirbet A., Lazár D., Kromdijk J., Govindjee: Chlorophyll $a$ fluorescence induction: Can just a one-second measurement be used to quantify abiotic stress responses? - Photosynthetica 56: 86-104, 2018.

Strasser R.J, Schansker G., Srivastava A., Govindjee: Simultaneous measurement of photosystem I and photosystem II probed by modulated transmission at $820 \mathrm{~nm}$ and by chlorophyll $a$ fluorescence in the sub $\mathrm{ms}$ to second time range. - In: Proceedings of the $12^{\text {th }}$ International Congress on Photosynthesis, Brisbane, Australia. CSIRO Publishing, Melbourne 2001.

Tsonev T., Velikova V., Yildiz-Aktas L. et al.: Effect of water deficit and potassium fertilization on photosynthetic activity in cotton plants. - Plant Biosyst. 145: 841-847, 2011.

Zhu X.G., Song Q.F., Ort D.R.: Elements of a dynamic systems model of canopy photosynthesis. - Curr. Opin. Plant Biol. 15: 237-244, 2012.

Appendix. Chlorophyll $a$ fluorescence parameters (CFPs).

\begin{tabular}{ll}
\hline CFPs & Description \\
\hline $\mathrm{DI}_{0} / \mathrm{CS}_{\mathrm{m}}$ & Dissipated energy flux per CS at $\mathrm{t}=\mathrm{t}_{\mathrm{Fm}}$ \\
$\mathrm{DI}_{0} / \mathrm{CS}_{0}$ & Dissipated energy flux per CS at $\mathrm{t}=\mathrm{t}_{\mathrm{F} 0}$ \\
$\mathrm{DI}_{0} / \mathrm{RC}_{\mathrm{f}}$ & Dissipated energy flux per RC at $\mathrm{t}=\mathrm{t}_{\mathrm{F} 0}$ \\
$\mathrm{dV} / \mathrm{dT}_{0}$ & Net rate of optical reaction centre closure at $\mathrm{t}=300 \mu \mathrm{s}$ \\
$\mathrm{dVG} / \mathrm{dT}_{0}$ & Net rate of optical reaction centre closure at $\mathrm{t}=100 \mu \mathrm{s}$ \\
$\mathrm{ET}_{0} / \mathrm{CS}_{\mathrm{m}}$ & Electron transport flux per CS at $\mathrm{t}=\mathrm{t}_{\mathrm{Fm}}$ \\
$\mathrm{ET}_{0} / \mathrm{CS}_{0}$ & Electron transport flux per CS at $\mathrm{t}=\mathrm{t}_{\mathrm{F} 0}$ \\
$\mathrm{ET}_{0} / \mathrm{RC}$ & Electron transport flux per RC at $\mathrm{t}=\mathrm{t}_{\mathrm{F} 0}$ \\
$\mathrm{~F}_{1}, \mathrm{~F}_{2}, \mathrm{~F}_{3}, \mathrm{~F}_{4}$, and $\mathrm{F}_{5}$ & Fluorescence intensity at $100 \mu \mathrm{s}, 300 \mu \mathrm{s}, 2 \mathrm{~ms}, 30 \mathrm{~ms}$, and P point, respectively \\
$\mathrm{F}_{\mathrm{m}}$ & Maximum fluorescence, when all PSII RCs are closed \\
$\mathrm{F}_{0}$ & Minimum fluorescence, when all PSII RCs are open \\
$\mathrm{F}_{0} / \mathrm{F}_{\mathrm{m}}$ & Quantum ratio for thermal dissipation at $\mathrm{t}=\mathrm{t}_{\mathrm{F} 0}$
\end{tabular}




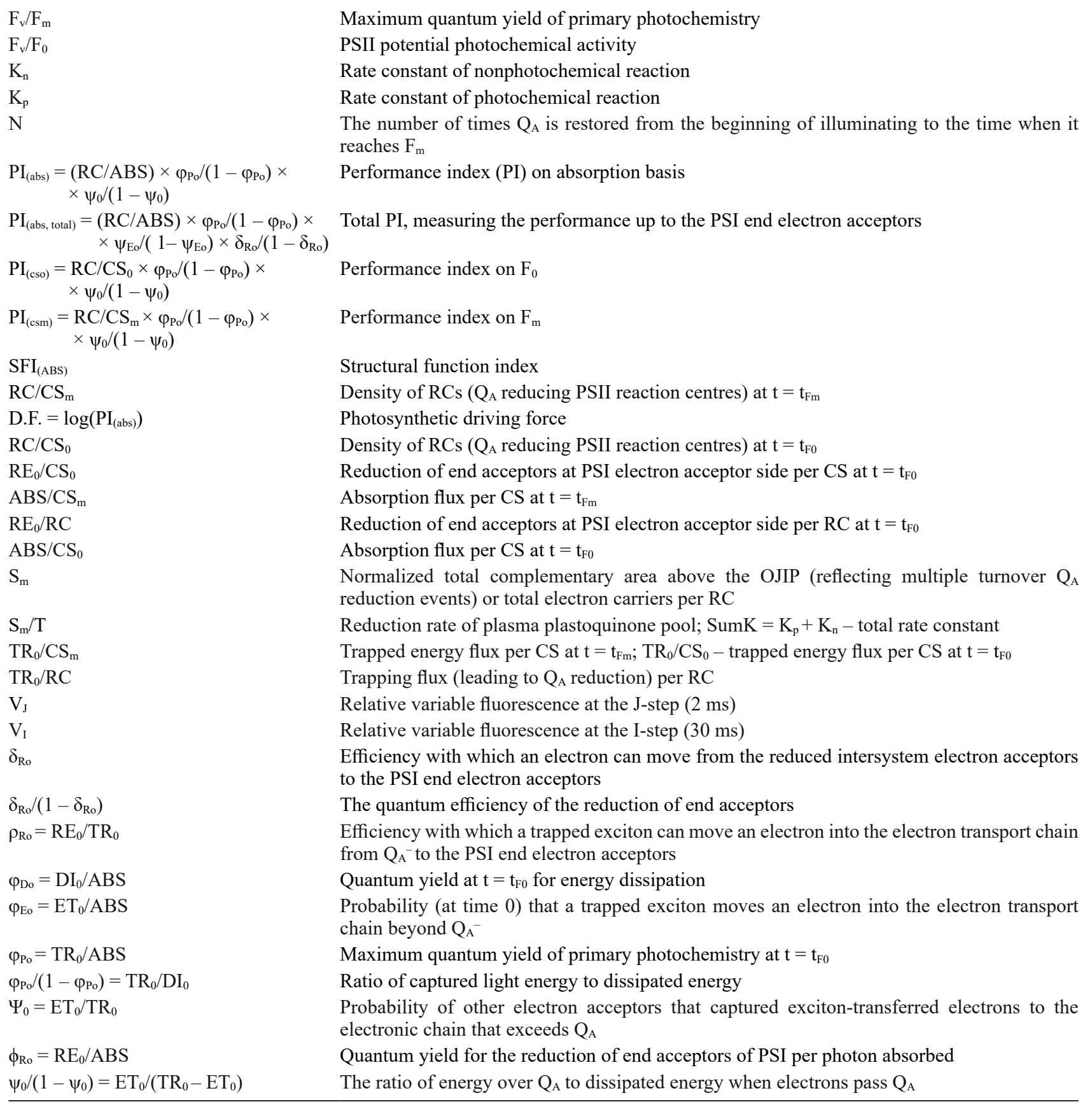

(C) The authors. This is an open access article distributed under the terms of the Creative Commons BY-NC-ND Licence. 